Технічні науки

УДК 66.047 .596

Туфекчі Валентин Іванович

acniрант

Національного університету харчових технологій

Вересоцький Юрій Іванович

кандидат технічних наук, дочент

Кафедра технологічного обладнання та комп'ютерних технологій проектування

Національний університет харчових технологій

\title{
РОЗПИЛЮВАЛЬНЕ СУШІННЯ МОЛОЧНИХ ПРОДУКТІВ - ДОСЛІДЖЕННЯ ШВИДКІСНИХ ХАРАКТЕРИСТИК ТЕПЛОНОСІЯ ТА ПРОДУКТУ В ДИСКОВОМУ РОЗПИЛЮВАЛЬНОМУ КОМПЛЕКСІ
}

Анотація. У обчислювальній гідродинаміџу (CFD) розпилювальних сушарок модель Ейлера-Лагранжа використовується для розрахунку рухів крапель, що розпилюються, $i$ тепло- $i$ масообміну між краплями $i$ повітряним потоком. Такі розрахунки виконуються для сотень і десятків тисяч крапель, щзо становлять розпилення в сушарці. Одним із обмежувальних факторів при сушінні масообміну $\epsilon$ дифузія вологи всередині частково висушених частинок. Щоб змоделювати цฺю внутрімню дифузію вологи, кожна частка представлена серією концентричних сферичних оболонок. За цими оболонками вирімується одномірне рівняння дифузї, щцоб отримати внутрішній розподіл $і$ дифузію вологи всередині кожної частки. Ключовою перевагою СFD $е$ можливість швидко проводити аналіз можливих варіантів та оптимізацію. Як приклад 
розглядалася сушарка із заданим набором умов подачі продукту та теплоносія. CFD-моделювання проводилося з метою знайти оптимальні умови для парметрів нагрівання повітря. Ключова інформачія, щуо представляє інтерес для оператора установки, може бути вилучена $з$ результатів CFD і представлена в візуальному представленні траєкторій частинок, щзо залишають сушильний комплекс. Виходячи з ичих результатів, оператор сушарки може легко вибрати оптимальні робочі умови, які дозволяють йому досягти бажаної якості продукту за мінімальних вumpam.

Ключові слова: сушіння, дисковий розпилювач, швидкість теплоносія, аеродинаміка, сушильний комплекс.

Аннотация. $\quad$ B вычислительной гидродинамике (CFD) распьлительных сушилок модель Эйлера-Лагранжа используется для расчета движений распьляемых капель и тепло- и массообмена между каплями и воздушным потоком. Такие расчеты выполняются для сотен и десятков тысяч капель, представляющих распьление в сушилке. Одним из ограничивающих факторов при сушке массообмена является диффузия влаги внутри частично выссушенных частии. Чтобы смоделировать эту внутреннюю диффузию влаги, каждая частицฺа представлена серией концентрических сферических оболочек. По этим оболочкам решается одномерное уравнение диффузии, чтобы получить внутреннее распределение и диффузию влаги внутри каждой частицьь. Ключевьм преимуществом CFD является возможность быстро проводить анализ возможных вариантов $u$ оптимизациию. $B$ качестве примера рассматривалась сушилка с заданным набором условий подачи продукта и теплоносителя. СFD-моделирование проводилось с цуелью найти оптимальные условия для нагревающуего воздуха. Ключевая информация, представляющуая интерес для оператора установки, может быть 
извлечена из результатов CFD и представлена в траекториях визуальном представлении частиц, покидающих сушильный комплекс. Исходя из этих результатов, оператор сушилки может легко выбрать оптимальные рабочие условия, которые позволяют ему достичь желаемого качества продукта при минимальных затратах.

Ключевые слова: сушка, дисковый распьлитель, скорость теплоносителя, аэродинамика, сушильный комплекс.

Summary. In computational fluid dynamics (CFD) spray dryers, the EulerLagrange model is used to calculate the motions of sprayed droplets and heat and mass transfer between droplets and airflow. Such calculations are performed for hundreds and tens of thousands of droplets representing spray in the dryer. One of the limiting factors in drying mass transfer is the diffusion of moisture within the partially dried particles. To simulate this internal diffusion of moisture, each particle is represented by a series of concentric spherical shells. For these shells, a one-dimensional diffusion equation is solved to obtain the internal distribution and diffusion of moisture within each particle. A key advantage of CFDs is the ability to quickly analyze potential options and optimize. As an example, we considered a dryer with a given set of conditions for supplying the product and the heat carrier. CFD simulations were carried out in order to find the optimal conditions for the heating air. Key information of interest to the plant operator can be extracted from the CFD results and presented in trajectories by a visual representation of particles leaving the drying plant. Based on these results, the dryer operator can easily select the optimum operating conditions to achieve the desired product quality at the lowest cost.

Key words: drying, disk sprayer, coolant speed, aerodynamics, drying complex.

Вступ. 3 метою подовження термінів зберігання продуктів використовуються різні технологічні прийоми, умовно об'єднані в групу 
"консервування". Найчастіше для «консервування» розчинів і суспензій використовують сушку - термічний процес видалення з твердих матеріалів, або розчинів вологи, що міститься в них, шляхом іiі випаровування. Цим сушіння відрізняється від інших методів видалення вологи, наприклад, шляхом поглинання, іiі хімічними реагентами або механічного відділення. Основним завданням сушіння є збільшення термінів зберігання готового продукту, зниження обсягу. У харчовій, хімічній та інших галузях промисловості сушіння - одна із найскладніших стадій процесу виробництва, від якої залежить якість готового продукту. Продукт, або матеріали доводиться сушити залежно від їх призначення для різних цілей. Ряд матеріалів піддається сушінню для зменшення їх ваги і здешевлення транспортування, зміни фізичних властивостей (наприклад, зменшення теплопровідності). Для надання матеріалам тих чи інших якостей використовують різні технології та способи сушіння: конвективна, радіаційна, сублімаційна, струмами високої частоти та інші [1;2; 3]. В даний час дрібнодисперсні харчові продукти одержують шляхом конвективного сушіння, наприклад молочна сироватка.

Аналіз останніх досліджень і публікацій. На практиці в літературі можна побачити, що жодна 3 представлених моделей не $є$ повністю вичерпною за наведеним вище визначенням. Проте можна виявити тенденцію до більш комплексних моделей в історичному розвитку моделювання розпилювальної сушарки. Існує зв’язок між складністю моделі та наявною потужністю комп’ютера. Складність опису потоків у камері прогресує від простого одновимірного постійного потоку через двовимірну вісь симетрії до повного тривимірного моделювання перехідних процесів. Існує також тенденція щодо кількості розглянутих процесів, наприклад, лише в останні роки було повідомлено про моделювання основної проблеми розпилювального сушіння це осадження продукту на стінки башні (4). Однак це лише широкі тенденції. Одночасно 3 
тривимірним моделюванням проводяться дослідження, що реалізують стійкі одновимірні моделі $(5,6,7,8,9)$.

Gluckert F.A. в 1962 (10) припустив, що оскільки найбільшим частинкам потрібно більший час сушіння, вони обмежують продуктивність камери, отже розрахунок швидкості теплопередачі до найбільших частинок обмежує швидкість теплопередачі сушарки. Проста модель продемонструвала хорошу відповідність із загальною швидкістю теплопередачі, виміряною в експериментальних експериментах 3 розпилювальною сушаркою. Sjenitzer в 1962 (11) представив просте графічне рішення, хоча і з надто спрощеними припущеннями про осьовий рух від спокою, монодисперсних крапель, які не зливаються i не розриваються, у одночасному струмі газу 3 постійною швидкістю, 3 постійними властивостями газу та рідкої фази, при постійній різниці температур газу і краплі. Hortig в 1970 (12) представляє метод приблизного розміру розпилювальної сушарки для частинок діаметром більше 100 мкм 3 розповсюдженням траєкторій на основі кута розпилення, використовуючи номограми. Miura T. та Ohtani S 1980 (13) припустили одновимірну модель газової фази (без радіальних градієнтів температури чи вологості), але двовимірні траєкторії частинок. Stein в 1973 (14) i Katta i Gauvin 1975, 1976 (15) продемонстрували, що прості диференціальні рівняння руху можна успішно використовувати для обчислення спірального руху частинок, що на чверть століття раніше, ніж вихровий процес був включений в моделі CFD.

Метою статті $\epsilon$ спрощення фізичної реальності в переважній більшості моделей розпилювальної сушарки, про які повідомляється в літературі, полягає в тому, щоб обмежити модель самою камерою розпилювальної сушіння. Незважаючи на те, що пристрій розпилювальної сушки часто має псевдозріджений шар, з'єднаний з вихідним отвором сушильної камери для видалення залишкової вологи, яке має потоки продукту, або рециркуляції дрібних фракцій 3 циклонів. Така система є 
просто занадто складною для детального моделювання в цілому. Розпилення зазвичай розглядається як окрема модель. Джерело попередньо сформованих крапель, потенційно з розподілом діаметра та/або імпульсу, $є$ граничною умовою впуску для моделі розпилювальної сушарки.

Результати дослідження. Коли модель обмежена камерою розпилювальної сушарки, у справжній розпилювальній сушарці одночасно відбувається багато фізичних процесів. Існує безперервний фазовий потік газу та дискретний фазовий потік крапель/частинок. Відбувається передача тепла від газу до крапель, а також транспортування вологи як всередині краплі, так і від краплі до газу. Всі ці процеси взаємодіють: однофазний потік газу відрізняється від двофазного потоку газу з інертними частинками, i знову інший, коли газ охолоджується і зволожується крапельками, що випаровуються. Частинки спочатку мають розподіл діаметрів, але в міру висихання у них з’являються додаткові розподіли вмісту вологи та форми, а також можуть змінюватися розміри внаслідок злиття, або розриву. Липкі частинки можуть утворювати відкладення на стінці камери.

Потрібна комплексна обчислювальна модель розпилювальної сушарки; рівняння руху для обох фаз; рівняння енергетичного балансу, що враховують міжфазний теплообмін i тепловіддачу від газу до навколишнього середовища через стінку камери; рівняння переносу вологи як всередині, так і зовні крапель, включаючи деякі форми концентрації прикордонного шару та моделі градієнтів температури; модель механічних властивостей твердої фази для врахування розвитку напружень при висиханні.

Моделювання розпилювальної сушарки 3 використанням Computational Fluid Dynamics (CFD).

Обмежена кількість повідомлених досліджень моделювання розпилювальної сушарки за останні п’ятнадцять років зосереджена насамперед на впровадженні CFD. Хоча існує певний сенс, у якому будь-яка 
числова модель розпилювальної сушарки за визначенням $\epsilon$ обчислювальною динамікою рідини, термін CFD став означати саме техніку, за допомогою якої складний фізичний об’єм - наприклад, камера розпилювальної сушіння - поділяється на дуже велику кількість багатогранних клітин. Рівняння руху потім розв’язуються чисельно в кожній комірці, і модель повторюється до тих пір, поки граничні умови кожної комірки не збігаються з критеріями прийнятності.

Характеристики параметрів моделі. Розрахунок №1:

Прийнявши наступні граничні параметри для продукта та теплоносія:

Швидкість подачі теплоносія в газорозподільний пристрій з жалюзійним регулюванням $=$ в 95 м/сек.

Швидкість вильоту продукту з розпилювального диску $=150$ м/сек.

Тиск вигрузки продукту з сушильного комплексу = -150 Па.

Температура теплоносія $=175^{\circ} \mathrm{C}$.

Температура продукту (сироватки) $=56^{\circ} \mathrm{C}$.

Граничний діапазон частинок продукту 5-150 мкм

Фізичні характеристики молочної сироватки:

- Густина $=1022 \ldots 1027 \mathrm{\kappa} / \mathrm{M}^{3}$

- В'язкість $=1,55 \ldots 1,65 \cdot 10^{3}$ Па $\cdot$ с

- Поверхневий натяг $=52 \cdot 10^{3} \mathrm{H} / \mathrm{M}$

Для аналізу процесу розпилювального сушіння 3 використанням додаткового підведення сушильного агента була проведена серія розрахунків, що виявляють вплив введення додаткових параметрів сушильного агента, а також частоти зміни його напряму та швидкості. В дослідженнях було проведено: аналіз кривих сушіння, отриманих розрахунковим шляхом, виявлено нові параметри технологічних режимів розпилювального сушіння при різному поєднанні керуючих впливів, корекція режимів залежно від зміни структурно-механічних властивостей продукту в даному випадку молочної сироватки. 


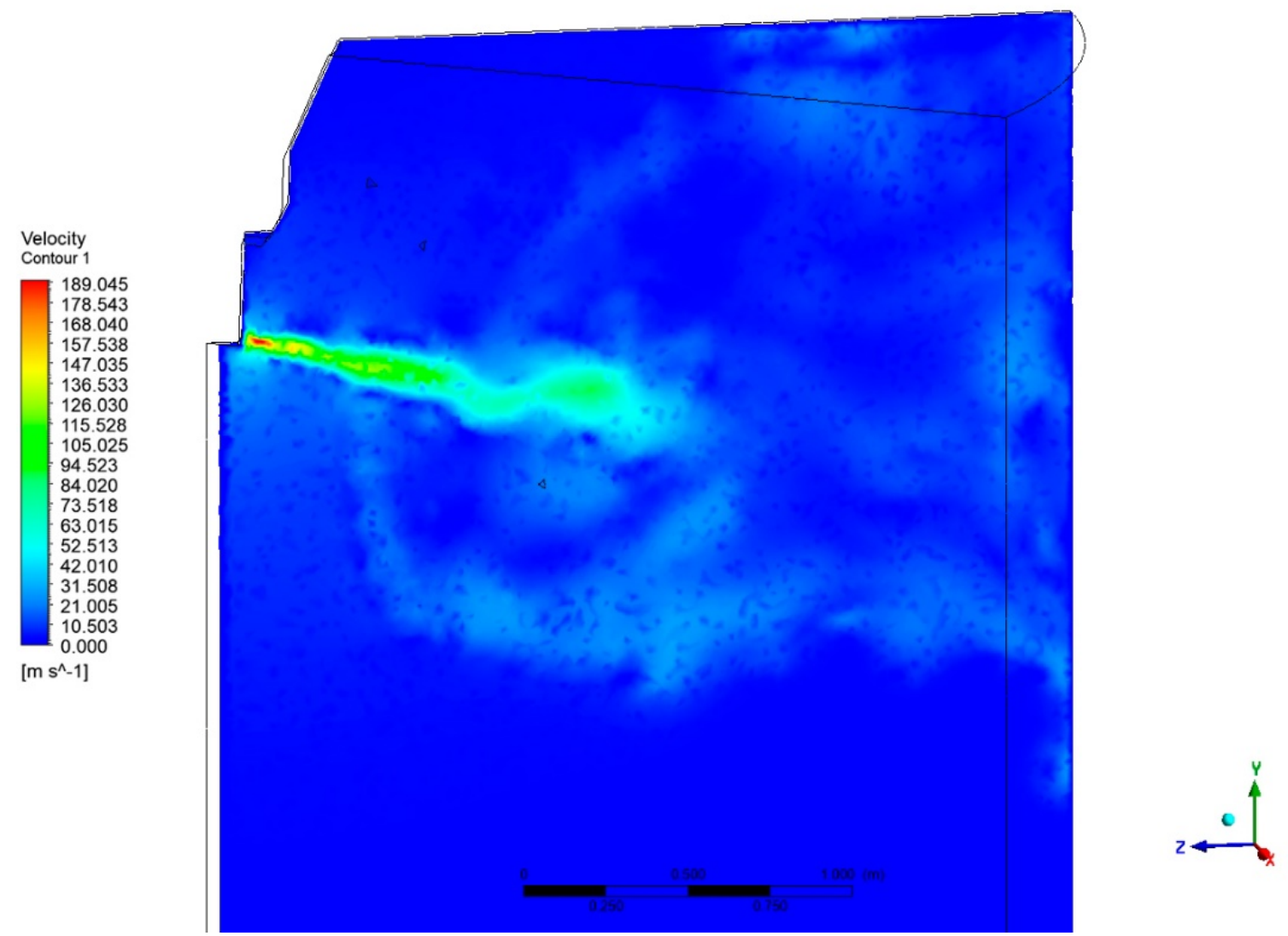

Рис. 1. Контур швидкості в секторі розпилювального комплексу в діапазоні параметру швидкості від 0 до 190 м/сек, при параметрі подачі теплоносія до факелу розпилу в значенні 95 м/сек.

Характеристики параметрів моделі. Розрахунок №2:

Прийнявши наступні граничні параметри для продукта та теплоносія:

Швидкість подачі теплоносія в газорозподільний пристрій з жалюзійним регулюванням $=$ в $115 \mathrm{~m} /$ сек.

Швидкість вильоту продукту з розпилювального диску $=150$ м/сек.

Тиск вигрузки продукту з сушильного комплексу $=-150$ Па

Температура теплоносія $=175^{\circ} \mathrm{C}$.

Температура продукту (сироватки) $=56^{\circ} \mathrm{C}$.

Граничний діапазон частинок продукту 5-150 мкм

Фізичні характеристики молочної сироватки:

- Густина $=1022 \ldots 1027 \mathrm{\kappa} / \mathrm{M}^{3}$ 
- $\mathrm{B}^{\prime}$ язкість $=1,55 \ldots 1,65 \cdot 10^{3}$ Па $\cdot \mathrm{c}$

- Поверхневий натяг $=52 \cdot 10^{3} \mathrm{H} / \mathrm{M}$
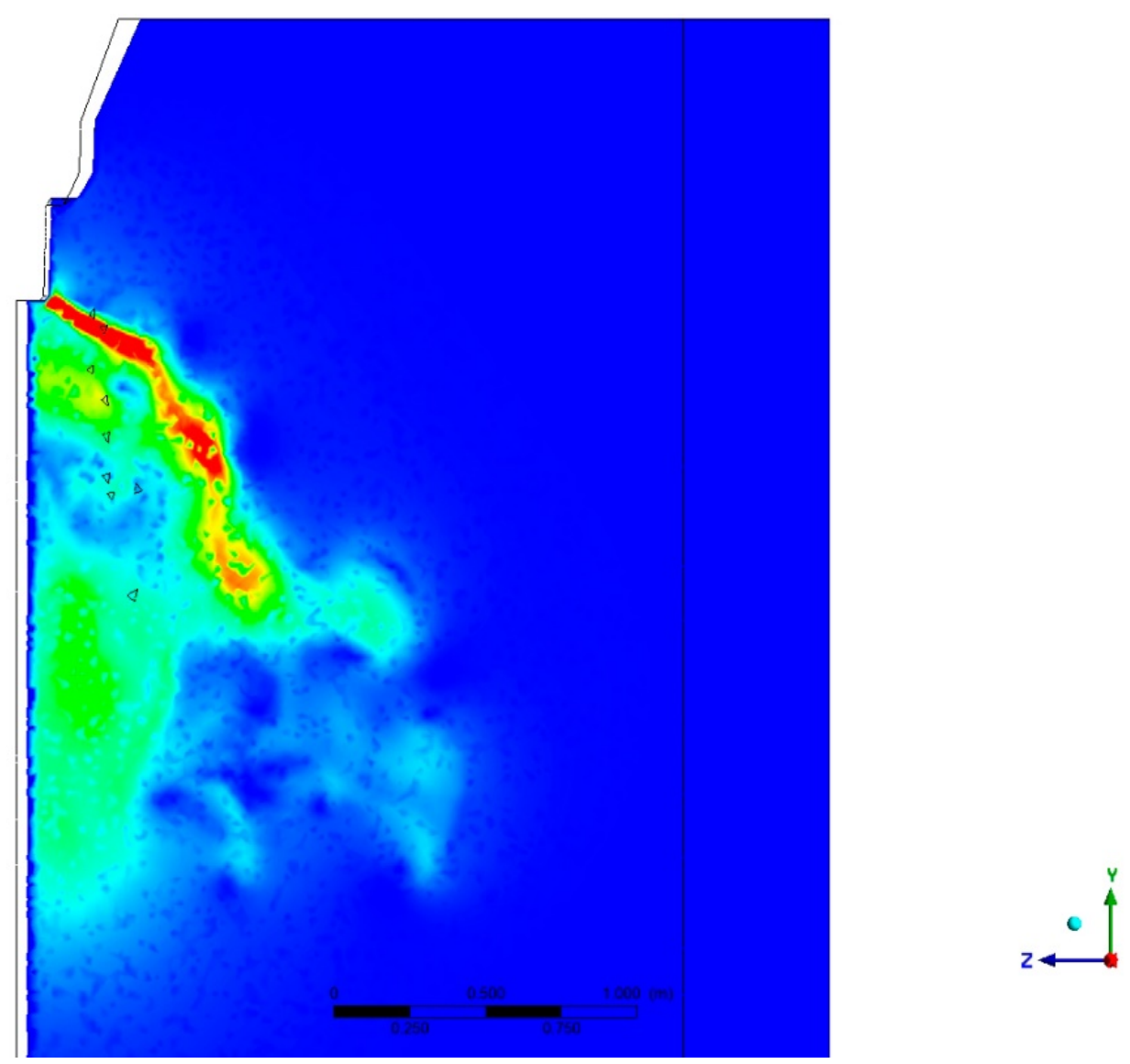

Рис. 2. Контур швидкості в секторі розпилювального комплексу в діапазоні параметру швидкості від 0 до 190 м/сек, при параметрі подачі теплоносія до факелу розпилу в значенні 115 м/сек. 


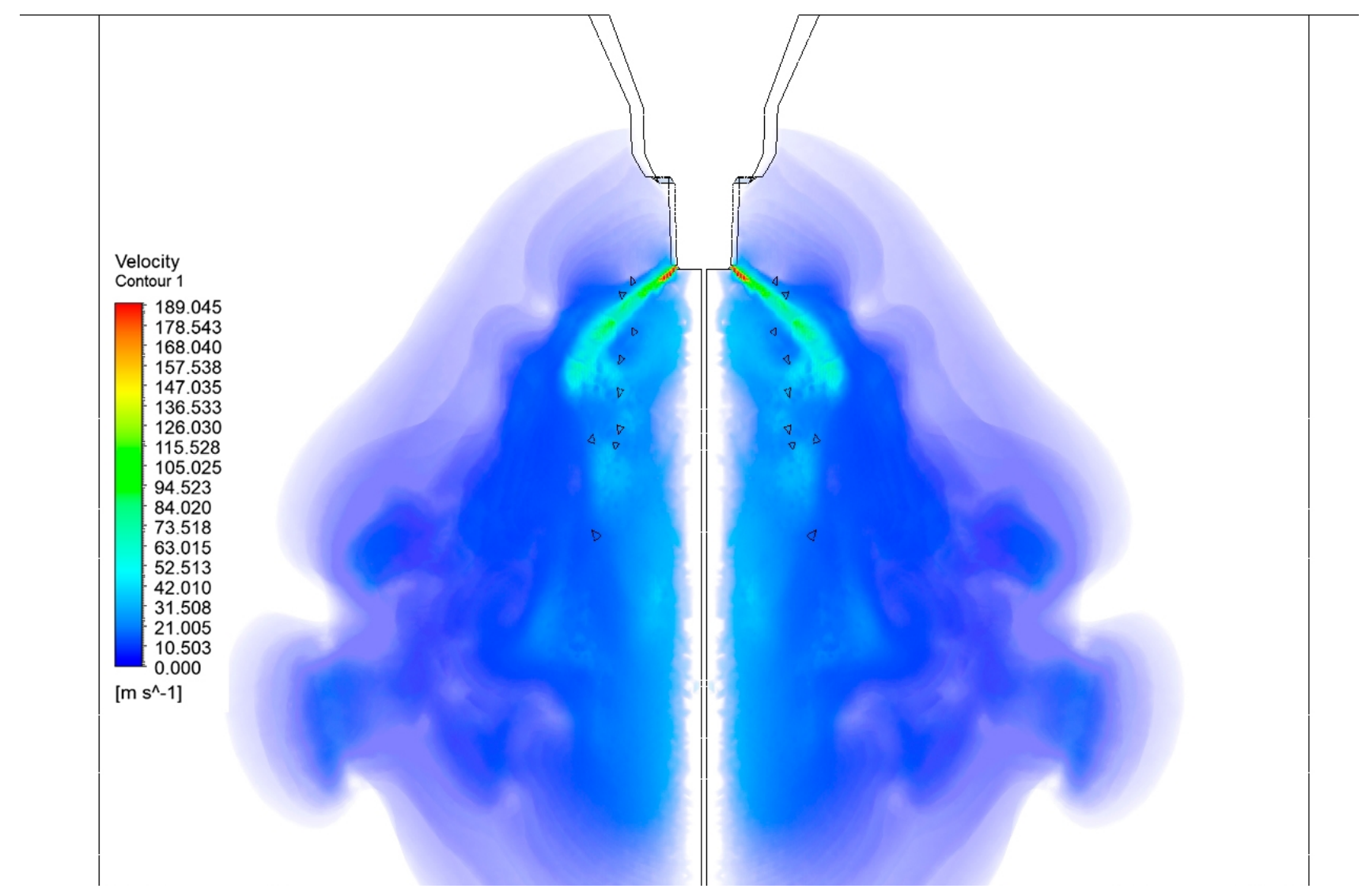

Рис. 3. Контур швидкості факелу розпилу продукту в дисковому розпилювальному сушильному комплексі

Висновки. На основі розробленої математичної моделі процесу розпилювального сушіння в нестаціонарному аеродинамічному потоці, масообміну та створеного на їі основі програмного засобу, проведено розрахунок прямоточної розпилювальної сушарки та виявлені оптимізовано технологічні параметри.

Використання отриманих результатів першого досліду (Рис 1), виявлено, що параметри швидкості та температури продукту для верифікації та ідентифікації частинок потребують оптимізувати процес розпилювального сушіння, так як основна частина продукту прямує до стінки башні, що в свою чергу є проблемою в довготривалій експлуатації без обслуговування.

Теоретично обгрунтоване та промоделювано використання жалюзійного регулювання аеродинамічного потоку при розпилювальному 
сушінні, що дозволяє скоротити час сушіння, розуміти траєкторії частинок продукту енергоємність процесу та підвищити харчову цінність готового продукту.

Виявлені оптимальні параметри розташування розпилювального диску, швидкості поперечного потоку і температури сушильного агента. Ці характеристики дозволяють проводити процес сушіння в режимі енергозбереження 3 отриманням високоякісного продукту. На підставі проведеної класифікації харчових продуктів виявлено особливості перебігу процесу сушіння різних груп продуктів залежно від технологічних режимів, що застосовуються.

Подальші моделювання згідно патенту на корисну модель (№ 148755), який уможливлює здійснення регулювання процесу в коливальному аеродинамічному потоці, інтенсифікує масообмін, та дає змогу налаштувати оптимальні параметри. В подальшому провівши виробничі випробування задача підтвердити можливість використання запропонованих технічних рішень, які підвищують продуктивність розпилювальної сушарки, знижують енерговитрати виробництва тони порошку, підвищують харчову цінність готового продукту, збільшують прибуток.

\section{Література}

1. Влияние температуры сушильного агента в прямоточной сушилке на качество сухого молока / Г.П. Сапрыгин, [и др.] // Сб. на-уч. тр. ОмСХИ. 1974. Т. 121. С. 8-11.

2. Крадинов В.Н. Получение сухого цельного быстрорастворимого молока с добавлением поверхностно-активных веществ и разработка промышленного оборудования для его осуществления: автореф. Дисс канд. техн. наук / В.Н. Крадинов. М.: ВНИМ, 1980. $24 \mathrm{c}$.

3. Любимов Д.В. Динамика поверхностей раздела в вибрационных 
полях / Д.В. Любимов. М.: Химия, 2003. 216 с.

4. Fletcher, D. F., GUO, B., Harvie, D. J. E., Langrish, T. A. G., Nijdam, J. J. \& Williams, J. (2006) What is important in the simulation of spray dryer performance and how do current CFD models perform? Applied Mathematical Modelling, 30(11), 1281-1292.

5. Negiz, A., lagergren, E. S. \& cinar, A. (1995) Mathematical models of cocurrent spray drying. Ind. Engg. Chem. Res., 34(10), 3289-3302.

6. Meerdink, G. \& van't Riet, K. (1995) Prediction of product quality during spray drying. Food and Bioproducts Processing, 73, 165-170.

7. Palencia, C., Nava, J., Herman, E., Rodriguez-Jimenes, G. C. \& Garcia-Alvarado, M. A. (2002) Spray-drying dynamic modeling with a mechanistic model. Drying Technology, 20(3), 569-586.

8. Truong, V., Bhandari, B. R. \& HOWES, T. (2005) Optimization of cocurrent spray drying process of sugar-rich foods. Part I-Moisture and glass transition temperature profile during drying. Journal of Food Engineering, 71(1), 55-65.

9. Chiou, D. \& Langrish, T. A. G. (2008) A comparison of crystallisation approaches in spray drying. Journal of Food Engineering, 88(2), 177185.

10. Gluckert, F. A. (1962) A theoretical correlation of spray-dryer performance. AIChE J., 8(4), 460-466.

11. Sjenitzer, F. (1962) The evaporation of a liquid spray injected into a stream of gas. Chem. Engg. Sci., 17, 309-322.

12. Hortig, H. P. (1970) Zur auslegung von sprühtürmen (The design of spraytowers). Chemie Ing. Tech., 42(6), 390-396.

13. Miura, T. \& Ohtani, S. (1980) Heat transfer characteristics in a concurrent spray dryer. Heat Transfer - Japanese Research, 79, 20-29.

14. Stein, W. A. (1973) Berechnung der verdampfung von flüssigkeit aus feuchten produkten im sprühturm (Calculation of evaporation of 
International Electronic Scientific Journal “Science Online” http://nauka-online.com/

liquids from moist products in spray towers). Verfahrenstechnik, 7(9), $262-265$.

15. Gauvin, W. H. \& Katta, S. (1976) Basic concepts of spray dryer design. AIChE Journal, 22(4), 713-724. 